\title{
Erratum to: Medicinal Plants and Environmental Challenges
}

\author{
Mansour Ghorbanpour and Ajit Varma
}

\section{Erratum to:}

M. Ghorbanpour and A. Varma (eds.),

Medicinal Plants and Environmental Challenges, https://doi.org/10.1007/978-3-319-68717-9

In the original version of the book, a new chapter "Biotechnological Approaches for In Vitro Conservation of Picrorhiza kurroa Royle ex Benth" has been included at the end. The erratum book has been updated with the change.

The updated online version of this book can be found at

https://doi.org/10.1007/978-3-319-68717-9 